\section{A PERSPECTIVE IN COMPUTER ETHICS}

\section{Pattarasinee Bhattarakosol $^{1}$}

\begin{abstract}
Since computers are counted as a part of life, the issue of computer-related ethics has been considered seriously. Although there have been many studies done and various guidelines had been announced over the decades, enforcement has been impossible. This paper presents a short description of computer ethics and discusses the impacts when ethics are infringed. The causes of breaking ethical guidelines have been raised. Solutions are proposed to solve these causes by obtaining the cooperation of the family and using doctrines.
\end{abstract}

\section{Introduction}

Originally, computers were invented to support mankind to perform tedious work. However, the improvement of technology has been very rapid and human needs are unlimited. Thus, computer efficiency is increasing as an exponential model from time to time. People learn to use computers in various applications. The results of using computer applications are generally acceptable and perfect. Therefore, computer applications have been developed to perform as many tasks as possible for people.

According to the capabilities of computers, computer technology has become a part of man's life. Consequently, the way of

1 Department of Mathematics, Faculty of Science, Chulalongkorn University. thinking and belief have changed. People have become more self-centered, careless, and shameless. They believe in objects, take what they can to survive and be happy. These changes have had a great impact on society, not only the computer world but the entire world.

Many institutes have shown concern and studied the word "computer ethics". Various definitions have been announced, and sadly they still cannot force the world to follow those steps. The degeneration of society has become severe and spread around the world.

In order to protect and detect the illegal actions from using computers, various techniques and laws have been installed. However, these solutions are only the solutions at the end points of those actions. Therefore, to be able to solve the problems of breaking down the computer ethics, the causes of the problems must be eliminated.

This paper presents the general description of the word "computer ethics" and the importance of these ethics in Section 2 and 3 , respectively. In Section 4, the classification of people involved in computer ethics will be explained. Additionally, Section 5 describes some important issues related to computer ethics, while Section 6 elaborates on problems resulting from a lack of computer ethics. Causes of transgressions in computer ethics and the solution to alleviate these causes are presented in Section 7 and Section 8. Section 9 is the conclusion of this paper.

\section{What is computer ethics?}

From the ten commandments of computer ethics stated by the Computer Ethics Institute [1], we can summarize that computer ethics have been established to 
protect people from any harm, grant privacy, guarantee safety, legality, human's rights, and social care. From the articles of [2], the issue of computer ethics has been a concern before the term "computer ethics" was used. However, the definitions of computer ethics from various researchers are not differences in meaning or scope of computer use.

\section{Why is computer ethics important?}

Presently, people use computers for all jobs that have to be done. Therefore, "TRUST" is the most important issue that computer systems have to provide to its customers. Unfortunately, the computer is heartless; it has no feelings and no thought of right or wrong since computers rely on commands and data that are entered by humans. Therefore, "TRUST" must refer to the trust that people can provide each other.

Although computers were invented to support life, there are two ways of using them. People use computers for their tasks, making their life easier, and gain benefits at the same time. In order to obtain high returns from any investment, computers can help their users to produce illegal documents that may not be able to trace. Thus, using a computer for any illicit process is as reliable as any lawful process.

According to the fact that computer applications are mostly standard and are produce based on software engineering ethics, the possibility that the command itself will work illegally is zero. Therefore, there is only one way that computers will present incorrect data, which is from the data entered.

Since computers help users to produce information and this information comes from data entered by people, the information content can be true or untrue. Some applications will have some data correction and detection that can detect a small range of incorrect data. However, this mechanism does not guarantee that the data entered is correct.

People use information to perform their work. For example, managers use information to manage the company, set management policy, or stock traders use information to make decisions on their investment. These usages are a part of the country's system. Therefore, if organizations obtain incorrect information, the negative impact can affect the entire country's business system. Finally, the negative results can spread to society. On the other hand, if organizations obtain correct data from using computers, positive outcomes can be achieved, and the entire world obtains the benefits. Thus, the results gained from computers can be both positive and negative, depending on how computers are used by society.

\section{Who should be involved in computer ethics?}

Computers work because of humans. So, everyone who uses a computer must be involved in computer ethics. There are many groups of people that are involved in computer usage.

The first group is technical people who implement computers for others. This group is the most powerful one that has technical knowledge to control computers. All commands that computer applications can perform are written by these technicians. Therefore, hidden processes can be embedded in the system easily, according to the technicians' responsibilities. 
The second group is the management level who has authority to approve the implemented computer system and its applications. People in this group have responsibility to determine the direction and policy of computer use in the organization. Thus, the legal or illegal implementation of computer applications must be acknowledged by these people.

The last group can be referred to as a group of people who are responsible for data entry from various sources. Data entry is very important for every user because the data will be the information used to drive organizations to success. As mentioned previously, incorrect data can be presented by two causes: program error, or data error. If the application is approved for its function and incorrect data are still presented, the entered data must be incorrect. Thus, computer ethics will deal with the case of incorrect data being put into the system intentionally.

People in these three groups can harm all rules of computer ethics in different ways. Consider a technician who has no loyalty to his company; he may put some codes that will deduct every $1 \%$ of the company's income. Therefore, the company will lose money on every income transaction. A similar case can occur for the manager's level, since a manager may request some important information from the company's database and sell it to the opposition. Consequently, the company is not secured. According to the fact that the people who input data into the system for information production are very important, the organization's stability depends on this input. So, a big disaster can occur to the organization if the management level obtains the wrong information from the organization's database.

\section{What are the important topics related to computer ethics?}

Since computer ethics focuses on human rights, there are many important issues that are directly related to computer ethics and need to be seriously considered. It is true that people who use computers are always concerned about their privacy. Thus, privacy and anonymity have become an important issue in this area. Moreover, intellectual property right is another topic that computer users have to be aware of. Furthermore, the professional responsibility of technicians that has a great impact on all users at all levels must be taken into consideration, as well as globalization, which is currently a hot issue. This article will discuss only some important issues that are directly related to people in society.

All users who use computers to perform their work need privacy, and would like to keep their work as secret as possible. Therefore, the user always uses a login name and password to protect the system from entry by others. So, these login names and passwords are keys to identify users. However, some users, such as students, may not want to be traced by their friends or teachers. Thus, they use anonymous names to hide their real names and actions. Thus, providing too much privacy and anonymity can have both positive and negative impacts on others.

When people hide their names to perform legal task under a standing of social ethics, there is no negative effect. On the other hand, the illegal tasks performed by a hidden user can ruin people and society in different ways and these actions may not be traceable. Thus, the issue of granting too much privacy and anonymity in using computers is a serious point. 
It is a fact that the computer is a great tool for people to do their job, be the job legal or illegal. Like any thing on earth, computers have a bright side and the dark side. Using computers to create a good community is an example of the bright side usage of computers, while using computers to perpetrate a crime is an example of the dark side. When a computer is used to commit a crime, it can be said to be an excellent tool that prevents users from being traced. Therefore, computer crime is another problem that the government must consider seriously.

Sometimes, technicians who have high skill must take their computer work intentionally. One thing that any technician must keep in mind is professional responsibility. This responsibility is the responsibility for other people and for society. There are many professional responsibilities in the computer area, such as professional responsibility in information technology and professional responsibility in software engineering. Although these have different names they are all related to computer ethics.

Because of the rapid development in the computer world, companies have to pay various expenses, such as license fees, updating fees, and maintenance fees. However, there are many hackers who love to crack popular software so users need not pay for the license and updating fees. Thus, the intellectual property (IP) rights of the software producer is ignored. The issue of IP is very important because the remuneration for software developers is obtained from the payment of IP. Therefore, when the IP is violated by anyone, the emolument of the software producer may be affected, the software company will not be stable, and developers may receive a low salary.
In the cyberworld, globalization is vital. However, the definition of the word "global" must be considered very carefully. Even though information on the Internet is open and unlimited in use, some negative aspects about globalization must be considered seriously. For example, since the information is spread around the world, some information may transgress someone's right. Thus, a global law must be established to protect people from any effects from improper Internet usage.

Although there are some negative impacts from the cybernet, some positive outcomes are also possible. Since the worldwide web (www) has become an information vein of the world, the "Cyberbusiness" or ecommerce has become a part of it. Thus, people can buy and sell their products from any corner of the world. Global law has an important role in this issue, since there must be something to guarantee this type of trade.

\section{What is the problem?}

While computers have become an essential factor for mankind, the effects also have had a huge impact on man's life cycle. People have changed their lifestyle in order to fit into the modern world of computers. With these changes, the art and culture of society have also changed; what people believed to be good in early times is worthless in the present time. People waste their lives for something that may not last, create social problems, and finally, may, destroy them. These are signs of the deterioration of society.

We can see that using computers with ethics already has had a great impact on society. So, if people use computers without ethics then one person can seriously hurt others with this wonderful tool. Thus, the problems created from lack 
of computer ethics are very critical problems for everyone in society.

\section{What are the causes?}

Although many institutes and researchers have tried to establish the parameters of computer ethics, such as the Ten Commandments of Computer Ethics [1] that are accepted as a standard for computer ethics, unfortunately, not every user follows these rules.

There are reasons why some people do not follow the defined map, such as to challenge, social enforcement, because of financial problems, or for self-esteem. The main reasons for breaking the rules of computer ethics are usually related to money and appreciations. As mentioned previously, society has changed. This change has also had some negative impacts on human thought.

Originally, every community has had something to believe in, called religion. Every religion taught their members to be good to other people and the world. So peace on earth could be maintained. Nevertheless, this belief has been altered and people are likely to believe in what they have seen more than what they have been taught. People have become selfcentered. There is less or no sharing, and no shame. Unfortunately, the number of these people is increasing, while the number of people who really believe in religion is decreasing.

Since people have no fear about infringing on the laws, they also have no shame about ethics. Thus, people will do things to serve their needs without considering the consequences. Regarding computers, these greedy people can perform their tasks easily, with completely good returns.

\section{What should be the solution?}

To find the solution to achieve the goals of computer ethics is similar to finding the way to control mankind, which is likely to be impossible. However, there is a design technique in the area of software engineering to obtain satisfaction from users. If the designers can understand the behavior of users and design software using those characteristics, then users will be the delivered software. This brings us to the solution of computer ethics. If we understand human behavior, it is possible to get into their minds, making them accept what we want them to accept.

It is a fact that humanity is very difficult to understand since people grow up with various backgrounds. Therefore, it is difficult to define the character of mankind in general so that computer ethics can be applied. However, there is the smallest unit in society, the family. Each family creates a model. Thus, if every family unit in any society originally has good morality and accepts the rules of computer ethics then every new member of those families will be taught to accept the same thing. Therefore, to succeed in having people of computer ethics, cooperation from all family units must be addressed first. This solution will take time. However, it will not be too late if this process starts now.

\section{Conclusion}

This paper has presented the general description of computer ethics and significant issues that have to be considered by all users. Serious outcomes can occur when computers are used with illegal intent. In the computer ethics issue, there are three significant groups that are directly involved. These three groups have 
different roles in computer applications and usage. The roles of these three groups lead to various points of discussion relating to computer ethics, such as privacy and anonymity, computer crime, and globalization. All these areas are related to the community and to sociology. People's attitudes and beliefs have changed, especially regarding religion. People are more selfish, greedy, and shameless. Thus, the rate of computer use without ethics is increasing, no matter how many computer ethics guidelines have been established.

In conclusion, the author believes that people break rules of computer ethics to serve their needs because of social changes and lack of belief in a positive doctrine. Therefore, it is difficult to implore everyone to follow the rules of computer ethics while they feel they have to survive in this world. However, the author does not conclude that it is impossible to create a good society with computer ethics; but to overcome this issue it must begin with the family unit, instead of commandments on the Net.

\section{References}

Barquin, R. C. 1972. In Pursuit of a Ten Commandments' for Computer Ethics. Computer Ethics Institute.

Stanford Encyclopedia of Philosophy. Computer Ethics: Basic Concepts and Historical Overview.

\section{Website}

http://plato.stanford.edu/entries/ethics computer/, 2001. 